Session 3275

\title{
The DO's and DO NOT's for Major Projects in an Introductory Design Course
}

\author{
Richard Bannerot
}

University of Houston

Introduction

A sophomore level course, "Introduction to Mechanical Design", has been a required course for mechanical engineering majors (but for the purposes of this paper it could just as well have been for all engineering students) at the University of Houston since 1980. Since 1991 it has been taught each fall and spring, to between 35 and 55 students, by the author of this paper. The course is usually the first engineering course taken by a mechanical engineering student. Therefore, part of the course objective is to introduce students to, and build their confidence in, problem-solving. The course is project oriented and, during a typical semester, one major group project and two or three minor projects (individual or group) are assigned. While the intent, extent and format of the minor projects change each semester, the format, structure and the evaluation process for the major projects (which change each semester) have evolved to a more or less steady state. While the course content includes a potpourri of topics, e.g., the design process, shop practice, manufacturing, creativity, ethics, statistics, intellectual property, codes and standards, personality issues (Myers-Briggs) and working in groups, the major project remains the single most significant part of the course counting for as much as $50 \%$ of the course grade. The major project is presented to the class in the second week of the course and continues throughout the semester. Among the delieverables are: a working device which satisfies a set of constraints and performs satisfactorily, written progress reports, group meetings with the instructor, initial testing (proof of concept), final testing in which success in approaching specified goals is measured, a final written report, a final oral presentation and a design evaluation. Group performance on all of these "requirements" contributes to the final grade for the project and removes much of the "pressure" for a device to "perform" at the final testing, i.e., the execution of the design process is viewed as an important part of the evaluation of the project. The experience gained from the twenty-one major projects over the past ten years has provided many useful lessons about the "DO's" and "DO NOT's" for project conception, development, expectations, management and evaluation. The purpose of this paper is to share some of 
these experiences and to present some general suggestions for successful projects. Issues that will be addressed include: appropriate projects, student expectations, formation and evaluation of groups, grading methodology, competition, design for assembly, written and oral reporting, design evaluation, esthetics, and the use of mentors.

\section{Course and Project Organization}

The three credit-hour course is organized as a two-hour lecture (for the entire class) one day each week and a three-hour "work session" limited to about 25 students each week. The syllabus is presented in Fig. 1 on the next page. On average about 50 students enroll each semester, so there are usually two "work sessions". The "work sessions" are used for various purposes including formal student presentations, prototype testing, shop tours, scheduled instructor meetings with individual groups, and "work on project time." On the first day of class, the students are told that in their "work session" that week they will be expected to make a three to five minute oral presentation. The topic is open, but they are told that it is preferred that they talk about themselves and most do. This experience serves two primary purposes: first, few of the students know anyone else in the class so these presentations allow the students to introduce themselves (very helpful since design groups will soon be formed) and second, several oral presentations are required during the semester and the more these are practiced the better.

The first lecture is used to put "design" in perspective with "engineering" and to introduce the design process. Machine tools, shop practice and manufacturing processes are reviewed in the lecture in the second week. The major project also begins with the distribution of the project description (usually a ten to twelve page document). A brief overview of the project is also given. Each "work session" is divided into four groups (about six students per group) and scheduled for a machine shop "experience". For the next two weeks each group will attend a two hour session in the Department machine shop in which they will participate (with one of the Department machinist) in the production of a simple metal part utilizing an engine lathe, a vertical mill, a vertical and a horizontal band saw, a drill press, grinders, and a tapping set. The operations of various other hand tools (e.g., calipers, micrometers, broaching set, etc.) and many of the accessories for the machine tools (e.g., various three and four jaw chucks, various bits, borers, taps, etc.) are also demonstrated. A handout is provided which describes the operations of all the standard shop tools. Shop drawings are discussed from the machinist's perspective. There is also a demonstration of an CNC machine.

This shop "experience" takes two weeks to accommodate all the groups. On their "off week" the students are encouraged to begin their preliminary ideation for the major project. The lecture in the third week continues a discussion of the design process and includes a (usually lively) discussion of the major project. Students are expected to be formed into their project groups by the lecture of the fourth week and each group provides the instructor a list of group members (limited to four), contact information and a preliminary group name. It is expected that the name of the group will be consistent 
$\underline{\text { date }}$ lectures

Aug 22 Introduction, Design Process, and Writing

Aug 27 Manufacturing and Shop Practice

Aug 29 Student Talks

Sept 3 LABOR DAY HOLIDAY

Sept 5 Shop Tours

Sept 10 Specifications

Sept 12 Shop Tours

Sept 17 Work on Project 2

Sept 19 Group Meetings with the Instructor

Sept 24 Personality Issues

Sept 26 Work on Project 2

Oct 1 Creativity

Oct 3 Group Meetings with the Instructor

Oct $8 \quad$ Ethics

Oct 10 Initial Testing for Project 2

Oct 15 Intellectual Property

Oct 17 Work on project 2

Oct 22 Codes and Standards

Oct 24 Group Meetings with the Instructor

Oct 29 Engineering Economy

Oct 31 Work on Projects 2 \& 4

Nov $5 \quad$ Final Testing for Project 2

Nov 7 Work on Projects $2 \& 4$

Nov 12 Work on Projects $2 \& 4$

Nov 14 Presentations for Project 2

Nov 19 Work on Project 4

Nov 21 THANKSGIVING HOLIDAY

Nov 26 Work on Project 4

Nov 28 Presentations for Project 4

Dec 3 Wrap up and Test
Project 1: Human Power

Project 2: Major Project

Project 3: Specifications Project 2: Form Groups

Project 1: Initial Submission

Project 3: Initial Sub

Project 2: PR \# 1 (thru Sept 26)

Project 2: Initial Testing

Project 1: Final Submission

Project 4: Son of Baseball Frenzy

Project 3: Final Submission

Project 2: PR \#2 (thru Oct 2

Project 2: Final Testing

Project 2: Presentations

Project 2: Final Report

Project 4: Presentation

Project 4: Final Report

Figure 1: Course Syllabus: MECE 2361: Design I, Fall, 2001

Proceedings of the 2002 American Society for Engineering Education Annual Conference \& Exposition Copyright (C) 2002, American Society for Engineering Education 
with the "spirit" of the design and will be reflected in the esthetics of the physical device produced and in their reports, e.g., logos (both written and oral). Groups are allowed to change names as their designs and understanding evolves.

The "work session" in the fourth week is free time for the groups to begin work on their projects. Each group is also introduced to its mentor (an undergraduate who has completed the course) and to the small shop available for the construction of prototypes. The shop provides a variety of hand tools, a place to work, but only a few power tools. The mentors supervise the small shop and schedule the work sessions for the groups as needed. Usually each mentor will take two groups. The mentor's main responsibility is to help and motivate (as needed) the groups and to report any apparent group dysfunction to the instructor. If the group prepares its reports in a timely manner, the mentor is available with feedback before "official" submission. The mentor does not take an active role in "leading" the group, but will offer suggestions, especially if unrealistic designs are beginning to emerge. For the most part the groups are not sufficiently organized to take full advantage of the opportunities provided by the mentors. The mentors are provided a "group" office with a phone, refrigerator, and study space and a separate room with computers, printers, etc. (This space is their perk.). The mentors are also available to assist the instructor during the testing and competition. The mentors do no grading.

During the fifth week "work session" each group must meet with the instructor for a half an hour and present an informal oral report on their progress and problems. Usually, group dysfunction issues are addressed at these sessions, both those self reported by the group and those identified by the mentors.

Formal, written progress reports are due in the sixth week and tenth weeks. Additional information can be found later in this paper.

The major activity for the seventh week is usually the Initial Test (or Test of Concept). A device capable of achieving a reduced set of objectives under a reduced set of constraints must be presented for testing in the "work session." The evaluation is "pass" or "fail". Groups successful in their first attempts are awarded "10" points (out of the 100 points for the project); fewer points are awarded for success in subsequent attempts. All successful groups are qualified to compete in the Final Test (the Competition) in four weeks. Unsuccessful groups (during the Initial Test) must demonstrate a successful design within the next week (receiving significantly reduced credit) or they are not allowed to participate in the Final Test. During the next three "work sessions" each group will meet with the instructor at least once, twice if the group is having trouble. Otherwise the "work session" time is available for project work.

The Final Test is usually scheduled in the eleventh week. The event is presented in the atrium of the Engineering Building and usually draws a crowd. The student newspaper and, on a newsless day, one of the local TV stations may show up. For the Final Test each device must be under a specified mass, must be deployed from a box of limited size 
and operate within a limited space. Details on the constraints and goals for the devices are presented in the next section under "Devices." The device must satisfy several operational constraints and attempt to maximize a Figure of Merit based on a series of performance goals. Multiple attempts are allowed, but devices endure penalties if not successful during the first set of attempts. The Final Test is worth 25 points (out of 100 for the project). Points are awarded according to the device's Figure of Merit and other potential bonus points, which are all performance measures, e.g., the least mass, the smallest device, and closest to the time goal.

The "work session" is free the next week as the groups prepare for their oral presentations. Each group in their normal "work session" for the thirteenth week will be given 20 minutes to present their "case" and to sell their device and its design. As part of the presentation each group must demonstrate that its device satisfies all constraints and performs satisfactorily. The presentation is worth up to 10 points and groups are encouraged to be innovative. Many dress in matching clothes and use PowerPoint. Each successfully performing device is impounded after the presentations and evaluated by the instructor. The major criteria for evaluation are: 1) concept (uniqueness and appropriateness of the design concept); 2) creativity (execution of the concept); 3) robustness (reliability) 4) esthetics (craftsmanship, cleanness, attention to the overall "spirit" of the device, etc.); 5) attention getting (interest, innovative, etc.) 6) the container (mostly esthetics) and 7) operations manual. The Design Evaluation is worth up to 20 points.

The next "work session" is free, and the Final Report (worth up to 25 points) is due in the fifteenth week.

\section{Objectives}

The intent of the major project is:

- to provide an opportunity to practice design

- to provide an early focus on design in the curriculum

- to demonstrate aspects of engineering, e.g., team building, planning, scheduling, communicating (orally, written, and pictorially), constructing, and selecting materials, that many in the class have not yet experienced.

- to provide an opportunity for a directed, cooperative group activity

- to allow students to experience the potential difficulties and rewards of working in a group environment.

- to encourage community building among class members by having them experience a common problem.

- to urge students to better appreciate the values and skills of others, including technicians and craftsmen (skill diversity appreciation)

- to help students to recognize the need for the assessment of available resources and skills within the group to assure success and reduce cost 
- to stress the importance of effective written, oral and graphic communication in expressing and conveying ideas both inside and outside of the group

- to have fun, and most do

Some of the Issues

Constraints and Goals

In separate exercises the students learn about design constraints and design goals. The preparation of detailed "target" specifications in the early design phase are practiced. As part of the documentation of their projects, the groups must prepare design specifications that clearly distinguish the difference between the "required" and the "desired" features of their devices. It is stressed that devices must satisfy all constraints and a figure of merit is developed which provides a quantitative measure of the closeness of the approach to the various goals.

\section{Group Formation}

Some design educators think that team membership should be determined randomly, while others argue that an effort should be made to create teams of equal capability. Some believe that students could be teamed with peers on their own academic level in order to minimize frustration and keep the workload in balance, or with peers of compatible personality using the results of psychological testing such as the MyersBriggs test (more on Myers-Briggs later). Some believe that students should be free to select their co-workers. Most of our students work either full or part time and do not live near the University. In a city as spread out as Houston, relative geographic location of team members can be a determining factor in the success or failure of a team. Long commutes and/or lack of reliable transportation can be serious disadvantages. In this class students choose their co-workers or are put into a pool for random group formation. (Few place themselves into this pool.) Since most of the students enrolled in the class have had no previous engineering courses, they rarely know their classmates. Therefore the student presentations on the second day of class (as previously noted) are important in providing an opportunity for the students to get to know each other.

\section{Group Size}

The optimal group size has been an issue for many instructors. The first time the author taught this course, the students were given the opportunity to form groups of any size up to four members. There were 45 students in the class and over twenty groups were formed. Several were one person groups. It is clear that many students do not want to work with a group. Each semester some students still request to work alone. Request denied! Groups of four have worked well. Six is definitely too large; two is definitely too small. One of the interesting benefits of the group projects, i.e., forcing students to work with strangers, is that many good relations are developed. Groups formed at random in the design class are seen working together in other classes and are commonly teamed together in the senior design course two or three years later. 
Varying Skill Levels

One of the most difficult issues associated with a design class requiring the construction of a device is the significant differences in the students' technical backgrounds, primarily construction skills and mechanical ability and knowledge. Surprisingly, a significant percentage of the students has had no exposure to basic hand tools or even to readily available materials, while others have access to and experience with well equipped machine or wood shops. Typically, twenty percent have extensive machine shop experience; half of those are currently working as machinists. Although knowledge of construction is essential to designers, the already overloaded engineering curriculum does not allow for extensive shop training, and students are thus expected to acquire some of these skills outside of class. These issues give rise to resentment on the part of some unskilled students who feel that they are put at a competitive disadvantage. More mature students recognize their weaknesses, team with students who complement them, and learn by the experience. In good teams, knowledge is shared among team members. The importance of a realistic quality assessment of the available resources and skills within the group is essential. Many of the more successful groups had limited resources, but were able to recognize this weakness and compensate by being extremely creative. As noted previously, a small work area is available to the groups.

Spread the "Pain"

A difficulty can arise in the design class when a group produces an unsuccessful device or no device at all even though it is clear that considerable effort has been expended. So that the grade for the project does not rest solely on the success of the device at a given time and place, the grading is spread out over the entire semester: progress reports, final written report, final oral report, test of concept, final test (competition), and an overall evaluation of the device after it has been demonstrated to perform satisfactorily.

\section{Discourage Last Minute Construction}

Clearly, last minute activity is a fact of design life. However, requiring the Initial Test or Test of Concept (in the seventh week) is an attempt to force the students to gain an appreciation of the difficulties of fabrication at a time when they can still profit from their mistakes. The Initial Test is a greatly simplified version of the Final Test given on a pass/fail basis and unsuccessful groups have additional time to retest. Hopefully, lessons learned will be carried over to the Final Test which is usually a high stress time.

Design for Assembly

For the last five years devices have been required to be initially confined in a relatively small container which the students build. The groups are given a limited "set up" time, typically three to five minutes, to deploy their devices. The containers are also judged. The main reason for restricting the size of the undeployed devices was to reduce the size and extent of the deployed device. The volume and weight constraints greatly increase the creativity necessary to be successful. 
Compete against the Clock

There is no "head-to-head" competition. Each group competes against the clock. The performance requirements are carefully stated as "constraints" (the absolute limits in time, size and weight) and the "goals" (the preferred time, size and weight). Credit is given on an absolute scale for satisfying the constraints, and on a relative scale, i.e., relative to other groups, for close approach to goals. The absolute scales relieve some of the pressure on the students but greatly increase the pressure on the instructor to define realistic limits and goals.

\section{Limited Operator Participation}

Automatic control or remote controlled devices would normally be preferred in a design competition. However, such devices require a level of sophistication (not to mention the expense) that is not reasonable to expect from beginning engineering students. There have been projects in the past in which "operators" were allowed a physical presence (releases, mechanical controls, etc.), but they can unfortunately play a role in the success of the device by overplaying and/or "forcing" the device. Operators seem to find a way to use their device in an unintended manner "in the heat of battle." For example, joints restricted to a single degree of freedom by the rules are sometimes forced to multiple degrees of freedom by an anxious operator. Likewise, structural failures may be "supported" by the operator in a manner not intended. These actions are difficult to control much less evaluate fairly. Therefore, the "operator" role is carefully defined, usually limited to a simple "release" at the beginning of the run.

\section{Written Reports}

Two progress reports and a final report are submitted. No specific format is required, but information is made available on report writing and the format possibilities are discussed in class. A list of topics to be covered in the progress reports and in the final report are provided. The reports themselves are viewed as design projects (a problem to be solved). Reports are read carefully and significant feedback on content and style is provided, especially in the first progress report. The reports are to contain or address: letter of transmittal, title page, abstract, logs of group meetings, plans, schedules, how have plans changed and why, how is work divided, neat and proper graphics, properly referenced tables, figures and equations, proper use of appendices and conclusions. Errors noted in the initial reports are expected to be corrected in subsequent reports. All previous reports are submitted as appendices to the current report. Careless writing and errors in grammar are not tolerated and considerable effort is made to correct all errors and, if necessary, to provide references to the University's Writing Center.

\section{Oral Reports}

Each group meets with the instructor at least twice prior to the Final Test and presents an informal oral report on progress and difficulties. The instructor questions each group member. The groups are also asked to report on any "dysfunction." These meetings have proven to be very helpful in identifying potential problems and increasing the quality of the students' work. Each group makes a "final" twenty-minute oral 
presentation to the class. Well-organized and rehearsed formal presentations are encouraged. But originality and creativity (in good taste) are also rewarded and groups are encouraged to be "entertaining". Both the group and the individuals are evaluated, with each person receiving written comments. The presentations are approximately two weeks after the Final Test and changes and improvement in the devices are allowed, in fact, encouraged in the two-week interval. During this presentation, the group must demonstrate its device satisfies all constraints, i.e., is successful. After the presentation all "successful" device are evaluated.

\section{Personality Issues}

A "lay" version of the Myers-Briggs temperament evaluation has been administered to this class each semester for the last ten years. An interesting and very consistent class profile has evolved ${ }^{1}$. In any event "diversity" is discussed in light of the results for the class. Groups are not formed based on these results. However, individual differences are discussed in hope that it will help group members to better understand how to interact with each other.

Devices

The major concern for the course is safety. As a result, projects are selected to minimize the potential for injury to the students during the construction and the performance stages. In the 1980's there were several student injuries related to the accidental release of powerful springs. Power for the projects is now usually limited to that derived from gravity. Occasionally small battery operated motors are allowed, but the motors are usually less than effective since they must be controlled automatically and gear boxes must be fabricated by the students. For the most part the devices must move something(s), e.g., baseball, softballs, golf balls, ping pong balls in a prescribed matter. The objective in the Final Test is to provide a device that satisfies all the constraints:

- deployed within a specified time from a six sided container,

- weigh less than a specified amount,

- perform the prescribed task in the given time window and in a specified space, and

- constructed by members of the group without the use of any prefabricated "systems" although components such as gears (but not gear boxes), hinges, pulleys, wheels, bearings, and shafts are allowed.

In addition, there are several goals: The device attempts to maximize a figure-of-merit function that prefers devices that most closely achieve a set of goals:

- minimal weight (down to one pound),

- minimal size of the container that the device is deployed from (down to one cubic foot), and

- minimal difference between the specified time and actual time for the task.

Example Problem Statement (Fall, 2000 project: the first page of an eleven page document ) 
Each group will design and fabricate a structure and all the auxiliary systems (hereafter called the "device") to move two golf balls (These must be official golf balls and provided by the group.), sequentially, in a specified time increment in a limited space and without operator intervention. The balls must travel, as a minimum, specified horizontal and vertical distances and each ball must begin and end its run at the same point (obviously a different point for each ball). The device will operate on top of a table provided by the instructor. The operator will initiate the movement of the first ball, but shall have no additional contact with the device, the table or the balls. The first ball must come to rest before the second ball begins its travel. Each ball must be in motion for at least ten seconds and, together, the two balls (traveling one at a time) must stay in motion for between 20 seconds and 40 seconds and travel a total vertical distance of at least ten feet and a total horizontal distance of at least twenty feet. Further, the device shall weigh less than ten pounds, shall be deployable from a six-sided container with side edge lengths less than 2.0 feet and shall remain within the space above the plane of the table formed by a parallelepiped, whose base is 30 inches by 60 inches and is three feet high. Evidence (e.g., sight or sound) of the motion of the balls must be provided throughout the run. There are no restrictions on the type of energy used during the performance, but there can be no external (outside the device volume) power source. However, designs using exclusively gravitational energy will be viewed more favorably than those using other forms of energy. Further, if multiple forms of energy are used, the greater the proportion of gravitational energy the better. Devices that use "excessive" energy (or power) will be penalized. Safety is of utmost importance, both to the people constructing the device, those operating it, and those observing its operation. "Unsafe" devices will be disqualified, and "safe" devices will be rated higher than those judged to be less safe. The performance of the device will be evaluated during three tests: the Initial Testing on October 4th, the Final Testing on November 1st, and during the Presentation on November 15th. Overall design evaluations will be conducted after the Presentation on November 15th. Details on the constraints, goals and evaluation processes are given in the accompanying document.

\section{The DO's}

Limit the operator influence; if possible allow the operator only to "release", with no active force and/or limit the degrees-of-freedom of the allowable force vector input. Make the activity visible from a distance of about fifty feet so that audience interest is maintained.

Emphasize esthetics for the devices and their containers. In the past groups have selected team names and the associate esthetics from an instructor given theme, e.g., the NFL teams, the NBA teams, the countries of the world, the states in the USA, etc.

Take extreme care in writing the problem description. Let others review it. Try to anticipate all possible (mis)interpretations and make no grammatical/spelling errors (to set an example and to establish a serious technical spirit). 
Clearly communicate to the whole class rule clarifications and revisions. Repeat profusely.

Place expectations (a goal) on expenditures. Require an itemized expenditure list including the estimated cost of "donated" items. Groups are not penalized for overspending unless it is excessive.

Give a lot of thought to what pre-fabricated components or parts will be allowed. Students will challenge all constraints and it is important to be consistent. Hopefully problems will be discovered early by the monitoring the progress of the designs. It is a sad moment when a device constructed with an illegal component is discovered during the Testing.

Stress that repeatability and robustness are important issues that are often overlooked.

Require that each group develop at least three distinctively different concepts early in the design process. These should be reported and their relative merits discussed in the Progress Reports. Stress that "one idea is a bad idea" and that alternative concepts are important in case the primary design is unconstructable.

Respect the effort of all students (who make an effort) even if the quality of their output is inadequate.

Expect arguments and complaints. Avoid possible misunderstanding and inconsistencies in the writing of the assignment and spell out all rules and regulations in a clear and precise manner. The project description should be complete before distribution; anticipate problems if modifications or revisions are necessary.

Insist on the fact that the instructor's interpretation of the rules prevail in case of controversy. The instructor is the client.

Develop a scheme to penalize those who do not contribute to the group. Peer evaluations of group members are effective. Ask each student to estimate the percent of the effort (other than his own) of each student in his group.

Make a big deal over the most successful designs. Attempt to develop a dedicated and prominent area in the Department for the display and recognition of them. Establish a tradition. Many students reveal early in the semester that their personal goal is for their design to be so recognized and displayed.

\section{The DO NOT'S}

Do not expect the projects to be easy to manage. 
Do not schedule the Final Testing the last week of class. Complaints will come from students and colleagues alike.

Do not expect too much. Normally two or three (of the ten to fifteen) groups with considerable fabrication experience "break the curve" by producing near perfect devices. On the other hand some groups will attempt to "get by" with cardboard and duct tape.

Do not expect machine-shop quality nor professional esthetics. Actually, esthetics is usually the downfall of most otherwise good devices.

Do not expect much interest from your colleagues. However, they are pleased that you are teaching a design course and they are not.

\section{Conclusions}

This paper has presented a brief overview of the philosophy used for and lessons learned from teaching a sophomore design course at the University of Houston for the past ten years. The students complain about the extra work but generally appreciate the opportunity to work in a group, to create a device, to receive feedback on their design skills and communication efforts, and to receive recognition from their peers for their efforts. One would think that creating a new project each semester with little concrete evidence about whether or not the requirements will be impossible to meet, unreasonable, or trivial would be a serious concern. In fact, this uncertainty about whether half the course would be failure was a large burden in the beginning. However, to this point each project has been at least a moderate success. There has been only one "failed" group (but several failed students) in ten years. The class drop out rate is less than 5\% after the first two weeks. Despite the extra time and effort on the instructor's part, the increased student-instructor interaction and the student enthusiasm make it all worthwhile.

References

${ }^{1}$ Richard Bannerot, "Identifying Psychological Diversity - the Use of a Myers-Briggs Type Indicator in Promoting Better Group Function," Proceedings of the 1997 Annual Conference of the ASEE Gulf Southwest Section, March 23-25, 1997, Houston, Texas, pp. 87-90.

\section{RICHARD BANNEROT}

Richard Bannerot is a professor of Mechanical Engineering at the University of Houston. His research interests are in the thermal science related areas, especially heat transfer and thermal system design. For the past ten year he has taught the required "Introduction to Design" course at the sophomore level to mechanical engineering students. 